\title{
Psychiatric emergency admissions during and after COVID-19 lockdown: short-term impact and long-term implications on mental health
}

Julia Ambrosetti ${ }^{1 *}$ (D), Laura Macheret ${ }^{1}$, Aline Folliet ${ }^{1}$, Alexandre Wullschleger ${ }^{2}$, Andrea Amerio ${ }^{3,4}$ (D, Andrea Aguglia ${ }^{3,4}$, Gianluca Serafini ${ }^{3,4}$, Paco Prada ${ }^{5,6}$, Stefan Kaiser ${ }^{2,5}$, Guido Bondolfi ${ }^{5,6}$, François Sarasin ${ }^{5,7}$ and Alessandra Costanza ${ }^{5}$

\begin{abstract}
Background: The 'lockdown' measures, adopted to restrict population movements in order to help curb the novel coronavirus disease 2019 (COVID-19) pandemic, contributed to a global mental health crisis. Although several studies have extensively examined the impact of lockdown measures on the psychological well-being of the general population, little is known about long-term implications. This study aimed to identify changes in psychiatric emergency department (ED) admissions between two 8-week periods: during and immediately after lifting the lockdown.

Methods: Socio-demographic and clinical information on 1477 psychiatric ED consultations at the University Hospital of Geneva (HUG) were retrospectively analyzed.

Results: When grouped according to admission dates, contrary to what we expected, the post-lockdown group presented with more severe clinical conditions (as measured using an urgency degree index) compared to their lockdown counterparts. Notably, after the lockdown had been lifted we observed a statistically significant increase in suicidal behavior and psychomotor agitation and a decrease in behavior disorder diagnoses. Furthermore, more migrants arrived at the HUG ED after the lockdown measures had been lifted. Logistic regression analysis identified diagnoses of suicidal behavior, behavioral disorders, psychomotor agitation, migrant status, involuntary admission, and private resident discharge as predictors of post-lockdown admissions.
\end{abstract}

Conclusions: Collectively, these findings can have implications concerning the prioritization of mental health care facilities and access for patients at risk of psychopathological decompensation in time of confinement policies, but above all, provide a foundation for future studies focusing on the long-term impact of the pandemic and its associated sanitary measures on mental health.

\footnotetext{
* Correspondence: julia.ambrosetti@hcuge.ch

'Department of Psychiatry and Department of Emergency, Emergency

Psychiatric Unit (UAUP), Geneva University Hospitals (HUG), 1211 Geneva,

Switzerland

Full list of author information is available at the end of the article
}

(C) The Author(s). 2021 Open Access This article is licensed under a Creative Commons Attribution 4.0 International License, which permits use, sharing, adaptation, distribution and reproduction in any medium or format, as long as you give appropriate credit to the original author(s) and the source, provide a link to the Creative Commons licence, and indicate if changes were made. The images or other third party material in this article are included in the article's Creative Commons licence, unless indicated otherwise in a credit line to the material. If material is not included in the article's Creative Commons licence and your intended use is not permitted by statutory regulation or exceeds the permitted use, you will need to obtain permission directly from the copyright holder. To view a copy of this licence, visit http://creativecommons.org/licenses/by/4.0/ The Creative Commons Public Domain Dedication waiver (http://creativecommons.org/publicdomain/zero/1.0/) applies to the data made available in this article, unless otherwise stated in a credit line to the data. 
Trial registration: Research Ethics Committee of Geneva, Registration number 2020-01510, approval date: 29 June 2020.

Keywords: Coronavirus, COVID-19 pandemic, Depression, Emergency department, Public mental health, Psychiatric admissions, Psychotic episode, Substance use disorder, Suicide, Suicidal behavior

\section{Background}

For more than one year since the World Health Organization (WHO) declared the novel coronavirus disease 2019 (COVID-19) a pandemic, countries around the world have implemented various policies in an attempt to mitigate its spread [1,2]. A growing body of scientific evidence has shed light on the impact of different socioeconomic and healthcare-related conditions on mental health [3-5]. For example, economic disruptions have triggered various psychological morbidities for the unemployed [6] while chaotic medical responses have fueled distress among healthcare workers [7-9]. Furthermore, global lockdown measures have had effects on psychological and emotional well-being for the general population $[10,11]$ as well as for vulnerable individuals (elderly, young adults, students, patients with chronic somatic disorders) [12-14], and those with a history of mental health disorders [15]. The impact of COVID-19 on the mental wellness of our society is, therefore, likely to be long-lasting and/or may become fulminant after the pandemic has subsided $[16,17]$.

Documenting the progression of such measures and their impact during the entire pandemic time, particularly during and post-lockdown periods, is of urgent importance to glean clinically-relevant insights that ensure optimal responses to future public health emergencies. Lockdown was first instated in Wuhan; initially faced with criticism for its harsh impact on society, this pandemic response model was subsequently implemented in many countries around the world [18]. Following the first case of SARS-CoV2 infection in Switzerland on February 25, 2020 [19], multiple clusters of infections were confirmed throughout the country [20], triggering the Federal Council to progressively adopt sanitary measures, including movement restrictions, the prohibition of large gatherings, and the mandatory closure of schools, stores, restaurants, and entertainment venues [21]. These lockdown-like measures were gradually relaxed in mid-May 2020 as the epidemiological situation improved in Switzerland.

Although several studies have examined the impact of the COVID-19 pandemic on the mental health of the general population worldwide [22, 23], little is known to date about the impact of removing lockdown measures on psychiatric admissions at the emergency departments (EDs). This information could inform on possible "rebound effects" following the imposition of lockdown measures as well as about their effects on the psychological well-being of both, general and clinical populations, because EDs are considered a frontline service that can very rapidly detect any changes [24-26].

Here, we analyze and compare the socio-demographic and clinical characteristics of patients admitted to the adult psychiatric ED of the University Hospital of Geneva (HUG) during two 8-week periods, the first coinciding with the lockdown and the second coinciding with the period immediately after the lockdown measures had been lifted. The aim of our study is to understand the possible impact of the lifting of lockdown measures on the mental health status of different patient classes.

\section{Methods \\ Study design}

A retrospective analysis of 1477 consultations at the psychiatric ED of the HUG, Geneva, Switzerland, between March 16 and July 5, 2020, was conducted. The HUG psychiatric ED is the only psychiatric ED in Geneva and forms part of the HUG general ED, which is in an urban ED. Patients can present directly to the psychiatric ED or be transferred from psychiatric/somatic outpatient facilities. All the admitted subjects were evaluated by a medical doctor and recruited without any particular inclusion/exclusion criteria. Informed consent from the patients was also waived because we argued that requesting consent would have introduced a selection bias. These consultations were divided into two subgroups based on admission date. Consultations performed from March 16 to May 10, 2020, were included in the lockdown group while those occurring between May 11 and July 5, 2020, comprised the post-lockdown group. The lockdown measures adopted in Switzerland were less severe than those implemented in other countries (private and public gatherings were prohibited, all non-essential businesses restaurants and bars were closed, but there were no strict stay-at-home orders). Given that the formal definition of lockdown differed from elsewhere, we demarcated the beginning and end of the lockdown in Switzerland by the respective dates when schools closed and reopened. Moreover, the schools reopening, as of May 11, was accompanied by the gradual reopening of non-essential stores.

All procedures in this study were carried out in agreement with the 2013 Declaration of Helsinki and 
reviewed and approved by the Research Ethics Committee of Geneva, Switzerland under the registration number 2020-01510 (approval date: June 29, 2020).

\section{Clinical assessment}

The patients' demographic and clinical information was collected according to previously published procedures $[26,27]$. The parameters included were age, sex, famil$\mathrm{ial} / \mathrm{marital} /$ residential statuses, diagnosis upon admission based on the EST ${ }^{\circ}$ (Echelle Suisse du Tri, HUG, Switzerland), one of the two screening platforms recommended by the Swiss Society for Emergency Medicine and Rescue, ED admission modes (referral by general practitioners/psychiatrists/other HUG departments, selfadmission, or by ambulance/police), admission times (8$19 \mathrm{~h}, 19-24 \mathrm{~h}$, or $24-8 \mathrm{~h}$; weekdays or weekends), ED stay duration (in hours), and the clinical outcomes (discharge decisions by an ED psychiatrist: involuntary/voluntary hospitalization, private resident discharge). The urgency degree of each admission was also assessed by the $\mathrm{EST}^{\oplus}$, which includes four levels of urgency: 1 - very urgent, life-threatening condition; 2 - pathological, nonlife-threatening but with the potential to rapidly deteriorate; 3 - pathological but not time-sensitive (e.g., the patient arrives in a stable condition); and 4 - medically stable and not requiring urgent care.

\section{Statistical analysis}

Clinical data, presented as means \pm standard deviations (SD) or counts and percentages, were assessed for normal distribution by the Kolmogorov-Smirnov test. Pearson's chi-square test with Yates' correction and a t-test for independent samples were employed for statistical comparisons. We used one variable admission period (lockdown period $=0$, post lockdown period $=1$ ). Then, we used a stepwise regression analysis with backward selection, i.e., we started by including all candidate variables and tested how the deletion of a variable affected the statistical significance of the fit. More specifically, we deleted those variables whose removal from the model resulted in the least statistically significant deterioration of the model fit and repeated this process until no further variables could be deleted. This approach was intended to eliminate potential collinearities among different predictors of patient admissions. We then used all significant variables for a univariate analysis and report only those variable that were statistically significant giving their odds ratio (OR) and confidence interval (CI) 95\%. All the analyses were performed using the Statistical Package for Social Sciences version 25.0 (SPSS Inc., Chicago, IL, USA) with a statistical significance threshold of $p<0.05$ (two-tailed). Regarding the interpretation of the specific variables, we used the same approach as in a previous study [27].

\section{Results}

\section{Descriptive statistics}

Overall, the HUG psychiatric ED provided 668 and 809 consultations during and after the lockdown, respectively. This represents a post-lockdown increase in consultations of $21 \%$ compared to the lockdown period. Based on a univariate analysis, we observed a statistically significant difference in the distribution of the severity of presentations based on the degree of urgency $(p=0.009)$. Notably, we observed a statistically significant postlockdown increase in suicidal behavior $(\mathrm{SB}),(p=0.029)$ and psychomotor agitation $(p<0.001)$ as well as an overall decrease in behavior disorder diagnoses $(\mathrm{p}<0.001)$. For "suicidal behavior", we only considered recent suicidal behavior, i.e., occurring in association with the current presentation at the psychiatric ED. From a socio-demographic point of view, the post-lockdown group contained more consultations by migrants $(3.8 \%$ vs. $0.7 \%, p<0.001)$. It should be noted that by "migrant" we mean a person who arrived in Switzerland from a very low-income country, often as a refugee or asylum seeker, i.e., they do not have a residence permit but only possess "migrant status" which means that they must live in special residences that are subsidized by the Swiss state. Other differences between the two subgroups are summarized in Table 1.

\section{Logistic regression}

A logistic regression analysis with ED admissions during the post-lockdown period as the independent variable generated the following ORs: 1.380 for suicidal behavior $(p=0.016), 2.089$ for psychomotor agitation $(\mathrm{p}<0.001)$, 1.636 for involuntary admission $(p=0.007), 4.386$ for migrant status $(p=0.003)$, and 1.404 for private resident discharge $(p=0.009)$. In contrast, behavioral disorder diagnoses were significantly positively associated with the lockdown period $(p=0.004, \mathrm{OR}=0.628)$ (Table 2$)$.

\section{Discussion}

To the best of our knowledge, this is the first report to document the post-lockdown and re-opening effects on the mental health of the clinical population during the COVID-19 pandemic in Switzerland. In a previous study conducted at the same institution, we investigated sociodemographic and clinical differences in psychiatric EDs admissions between pandemic-free and during the COVID-19 pandemic periods, using data from the same periods in 2016 and 2020, respectively [27]. We found a reduction in psychiatric $\mathrm{ED}$ admissions during the COVID-19 pandemic, and the admissions were positively associated with living alone and more severe psychiatric conditions (including the involuntary admissions modality). During the pandemic period, more diagnoses included suicidal behavior, psychomotor agitation, and 
Table 1 Comparison of sociodemographic and clinical characteristics of patients admitted to the psychiatric emergency department (ED) during the "lockdown" and "post lockdown" period in 2020

\begin{tabular}{|c|c|c|c|c|}
\hline Socio-demographic and clinical characteristics & $\begin{array}{l}\text { "Lockdown" } \\
(N=668)\end{array}$ & $\begin{array}{l}\text { "post lockdown" } \\
(N=809)\end{array}$ & Chi-squared/t-test & $p$-value \\
\hline Female Gender, N (\%) & $345(51.6)$ & $399(49.3)$ & .792 & .373 \\
\hline Current age, year, mean \pm SD & $39.81 \pm 16.71$ & $40.13 \pm 17.33$ & .358 & .720 \\
\hline \multicolumn{5}{|l|}{ Familial status, N (\%) } \\
\hline Unmarried/not in relationship & $387(58.1)$ & $453(56.2)$ & \multirow[t]{4}{*}{.577} & \multirow[t]{4}{*}{.902} \\
\hline Married/in a relationship & $130(19.5)$ & $168(20.8)$ & & \\
\hline Separated/divorced & $129(19.3)$ & $159(19.7)$ & & \\
\hline Widowed & $21(3.1)$ & $26(3.3)$ & & \\
\hline \multicolumn{5}{|c|}{ Residential status (where the patient comes from to be admitted to the ED), $\mathrm{N}(\%)$} \\
\hline Private residence & $530(79.3)$ & $645(79.7)$ & \multirow[t]{4}{*}{18.725} & \multirow[t]{4}{*}{$<.001^{*}$} \\
\hline Foster home, hotel & $80(12.1)$ & $91(11.2)$ & & \\
\hline Homeless & $53(7.9)$ & $42(5.2)$ & & \\
\hline Migrants & $5(0.7)$ & $31(3.8)$ & & \\
\hline \multicolumn{5}{|l|}{ Referral source, N (\%) } \\
\hline Private psychiatrist & $5(0.7)$ & $4(0.5)$ & \multirow[t]{7}{*}{8.441} & \multirow[t]{7}{*}{.208} \\
\hline General practitioner & $13(1.9)$ & $28(3.5)$ & & \\
\hline HUG & $19(2.8)$ & $18(2.2)$ & & \\
\hline Self-referral & $249(37.3)$ & $305(37.7)$ & & \\
\hline Police & $75(11.2)$ & $68(8.4)$ & & \\
\hline CAMSCO & $2(0.1)$ & $4(0.5)$ & & \\
\hline By Ambulance & $305(45.7)$ & $382(47.2)$ & & \\
\hline \multicolumn{5}{|l|}{ Urgency degree, according to EST ${ }^{\oplus}, \mathrm{N}(\%)$} \\
\hline Degree 1 & $126(18.9)$ & $212(26.2)$ & \multirow[t]{4}{*}{11.474} & \multirow[t]{4}{*}{$.009^{*}$} \\
\hline Degree 2 & $303(45.4)$ & $336(41.5)$ & & \\
\hline Degree 3 & $206(30.8)$ & $227(28.1)$ & & \\
\hline Degree 4 & $33(4.9)$ & $34(4.2)$ & & \\
\hline \multicolumn{5}{|l|}{ Diagnosis, N (\%) } \\
\hline Psychotic episode & $31(4.6)$ & $31(3.8)$ & \multirow[t]{8}{*}{49.333} & \multirow[t]{8}{*}{$<.001^{*}$} \\
\hline Manic/hypomanic episode & $17(2.5)$ & $11(1.4)$ & & \\
\hline Depression/anxiety & $175(26.1)$ & $197(24.4)$ & & \\
\hline Suicidal behavior & $141(21.1)$ & $210(26.0)$ & & \\
\hline Substance use disorder & $62(9.3)$ & $52(6.4)$ & & \\
\hline Behavioral disorder & $126(18.9)$ & $86(10.6)$ & & \\
\hline Psychomotor agitation & $52(7.8)$ & $127(15.7)$ & & \\
\hline Somatic problem & $64(9.7)$ & $95(11.7)$ & & \\
\hline \multicolumn{5}{|l|}{ Arrival hour, N (\%) } \\
\hline $8-19 h$ & $329(49.3)$ & $413(51.1)$ & \multirow[t]{3}{*}{.742} & \multirow[t]{3}{*}{690} \\
\hline $19-24 \mathrm{~h}$ & $206(30.8)$ & $248(30.7)$ & & \\
\hline $24-8 h$ & $133(19.9)$ & $148(18.2)$ & & \\
\hline \multicolumn{5}{|l|}{ Arrival day, N (\%) } \\
\hline Weekday & $465(69.6)$ & $578(71.4)$ & \multirow[t]{2}{*}{.594} & \multirow[t]{2}{*}{.441} \\
\hline Weekend & $203(30.4)$ & $231(28.6)$ & & \\
\hline \multicolumn{5}{|c|}{ Type of discharge (where the patient is referred at the time of discharge from the ED), N (\%) } \\
\hline Voluntary admission & $107(16.0)$ & $90(11.1)$ & 11.418 & $.010^{*}$ \\
\hline
\end{tabular}


Table 1 Comparison of sociodemographic and clinical characteristics of patients admitted to the psychiatric emergency department (ED) during the "lockdown" and "post lockdown" period in 2020 (Continued)

\begin{tabular}{|c|c|c|c|c|}
\hline Socio-demographic and clinical characteristics & $\begin{array}{l}\text { "Lockdown" } \\
(N=668)\end{array}$ & $\begin{array}{l}\text { "post lockdown" } \\
(N=809)\end{array}$ & Chi-squared/t-test & $p$-value \\
\hline Involuntary admission & $86(12.9)$ & $130(16.1)$ & & \\
\hline Private residence & $396(59.3)$ & $510(63.0)$ & & \\
\hline Others & 79 (11.8) & $79(9.8)$ & & \\
\hline Duration of visit, in hours mean \pm SD & $6.46 \pm 6.36$ & $5.99 \pm 5.51$ & -1.528 & .127 \\
\hline
\end{tabular}

Abbreviations: CAMSCO, Consultation Ambulatoire Mobile de Soins Communautaire; HUG, University Hospital of Geneva; * to $p<.05$. Familial status: missing data $(N=4)$

behavioral disorders were observed [27]. Therefore, we expected that - similar to pandemic-free period - lifting the lockdown measures would result in a decrease in serious psychiatric conditions. However, the results presented in this study do not match these expectations but indicate that more severe clinical conditions (according to the $\mathrm{EST}^{\varpi}$ urgency degree) were treated post-lockdown compared to during the lockdown. We also found a significant positive association between involuntary admissions and the post-lockdown period. While research on this topic is still limited, this observed increase in more severe and involuntary admissions is consistent with our observation of more severe clinical presentations (including the diagnosis of psychomotor agitation) postlockdown. This could be the result of a worsening mental health status in individuals with pre-existing psychiatric conditions during the lockdown due to reduced access to mental health services and the loss of social connections which would in turn lead to the observed post-lockdown increase in admissions [6, 7, 9, 14].

At the same time, alongside the increase in involuntary admissions in the post-lockdown period, which suggests more serious clinical situations, we have surprisingly observed an increase in discharges to private residences, which suggests less serious clinical conditions instead. We hypothesized that this finding was attributable, in the post-lockdown period, to the reopening of public psychiatric outpatient settings as well as the increased

Table 2 Backward logistic regression analysis of the relationships between potential explanatory variables and psychiatric ED admissions in the "post-lockdown" period

\begin{tabular}{llll}
\hline & $\boldsymbol{p}$-value & OR & $\mathbf{9 5 \%}$ Cl for EXP \\
\hline Suicidal behavior (SB) & $.016^{*}$ & 1.380 & $1.062-1.793$ \\
Behavioral disorder & $.004^{*}$ & .628 & $.458-.862$ \\
Psychomotor agitation & $<.001^{*}$ & 2.089 & $1.454-3.002$ \\
Migrant & $.003^{*}$ & 4.386 & $1.680-11.449$ \\
Involuntary admission & $.007^{*}$ & 1.636 & $1.145-2.339$ \\
Discharge to private residence & $.009^{*}$ & 1.404 & $1.090-1.808$ \\
\hline
\end{tabular}

Abbreviations: * to $\mathrm{p}<.05$

Legend: lockdown period $=0$, post lockdown period $=1$ availability to receive patients from private psychiatrists and family physicians.

The analysis performed in this study revealed a postlockdown increase in suicidal behavior. In other studies, increased suicidal behavior and mental health problems have been observed in different regions of the world during the lockdown period $[28,29]$, with some exceptions that could potentially be attributed to decreased help-seeking and hospital admission rates during these times of restricted activities [30] or other resiliency factors that protect against lockdown-induced psychiatric complications [23, 31]. McIntyre and colleagues [30] performed a longitudinal analysis of suicide rates in a cohort of 760 psychiatric ED admissions in Ireland during the early and late phases of the lockdown. They observed a sharp decrease in suicidal behavior during the early months of the lockdown, followed by a compensatory increase in suicidal behavior in the subsequent months peaking as the lockdown measures began to be removed. These findings are consistent with those reported in our study and support the hypothesis about the long-term impact of a lockdown on suicidal behavior that persists even after lockdown measures have been lifted. Several factors have been found to contribute to suicidal ideation and behavior, including, also in the long-term, the presence of economic stressors, increased consumption of addictive substances (drugs and alcohol), domestic violence, intense exposure to anecdotes of pessimism and helplessness, and persistent feelings of entrapment, isolation, and loneliness [32-34]. All of these factors can interact and have a synergistic effect, thus creating a vicious circle [35].

It should be noted that all the aforementioned studies are rather heterogeneous in that they employed different sampling approaches and methodological instruments and are therefore difficult to compare. Moreover, the situation is still evolving as were are still entering new phases of the pandemic (new lockdown and postlockdown cycles). However, based on the most recent summary analyses, two dynamics seem to emerge: higher lockdown rates of suicidal behavior in less industrialized countries and lower lockdown rates of suicidal behavior in more industrialized countries [36, 37]. 
In contrast to our findings, some studies found that the lifting of the lockdown had no significant impact on mental health [38, 39]. Richter and colleagues recently reviewed the literature on mental health problems in general (and not only clinical) populations of several countries during and after the first lockdown [23]. Despite methodological inconsistencies between the included studies, they could report a slight overall decrease in mental health disorders and suicidal behavior after the first lockdown had been lifted. This result differs from our findings and may be due to the fact that the studies included in their review employed different sampling approaches and methodological instruments (e.g., self-reporting and online surveys vs. hospital admissions). Also, socio-economic differences, health policy-related issues, and cultural factors of resilience (e.g., social support, education level and psychological flexibility) may also affect an individual's susceptibility to the negative impacts of a lockdown [23, 35]. Furthermore, while we only included a very narrow part of the general population, namely individuals admitted to a psychiatric emergency department, the results by Richter and colleagues are based on studies that included a much broader spectrum of the general population.

From a socio-demographic viewpoint, our study revealed a significant increase in the number of migrants being admitted to psychiatric EDs in the post-lockdown period. This phenomenon might be attributed to the accumulating healthcare burden in this demographic group throughout the pandemic, particularly during the lockdown period, where the impact has been demonstrably prominent. For example, studies focusing on migrants reported an increase in mental health disorders in this demographic $[40,41]$. Sanitary measures associated with the lockdown have brought the lives of many migrants to a standstill as they faced increased precariousness, financial constraints, and stigmatization by the non-migrant community. Furthermore, in some migrants' communities, preventative social distancing measures could not be implemented due to a lack of living space, which lead to numerous infection outbreaks. Thus, migrants are more susceptible to the psychological and emotional trauma of the COVID-19 pandemic. These observations might explain the influx of patients with migration background to our psychiatric ED during the post-lockdown period, i.e., once mental health access began to normalize. However, increased psychiatric ED admissions of migrants during the post-lockdown period cannot be explained by mental health or psychological issues alone and additional studies are required to elucidate the underlying associations.

Collectively, these findings emphasize the urgent need to provide access to mental healthcare during lockdowns, particularly for those who are more likely to suffer from psychiatric complications to prevent their manifestation during the post-lockdown period. Moreover, these findings suggest that additional attention should be paid to psychiatric conditions associated with involuntary admissions, severe clinical presentations, and suicidal behavior at psychiatric EDs during postlockdown periods so as to be properly prepared for such cases.

These objectives could be achieved by various means, including increasing the mobility of psychiatrists and nurses for in-home care, equipping psychiatric ED with high isolation standards against infections, and the use of telepsychiatry, defined as "the delivery of mental health care in the form of live and interactive videoconferencing" [26, 42]. In the context of telepsychiatry, patients could be evaluated and advised for treatment remotely. Telepsychiatry could provide uninterrupted care for psychiatric patients in real-time to help them cope with mild psychiatric issues during lockdowns so these problems will not transform into more severe clinical presentations in the long term (i.e., post-lockdown period). Furthermore, telepsychiatry could be considered a remote support mechanism to generate a sense of interconnectedness for patients who are suffering from loneliness, hopelessness, and helplessness, which have been significantly associated with increased suicidal behavior risk $[43,44]$. Of particular relevance to psychiatric EDs [45], remote services can be implemented by various means, and in an unexpectedly fortuitous manner, the COVID-19 pandemic has created an opportunity to utilize this technology to improve mental health access, care quality, and immediacy for psychiatric patients.

\section{Limitations}

This study needs to be interpreted in the light of several limitations. First, given its being retrospective and single-center, the findings need to be validated in a more diverse patient population before they can be generalized to other contexts. Secondly, two relatively brief periods of 8 weeks (for a total of 16 weeks) were compared and it is difficult to precisely delineate the differential impact of acute vs chronic lockdown and/or reopening on the frequencies of psychiatric ED admissions and their characteristics. Third, unlike many other countries with severe lockdowns, sanitary measures in Switzerland are more flexible with the absence of strict stay-at-home orders; these variable lockdown protocols might differentially impact the clinical features of psychiatric ED admissions, which would limit the representability of our findings. Fourth, these findings are associated with the initial lockdown wave and COVID-19 infections and, therefore, they only provide limited insight into the long-term impact of multiple waves of infections and lockdowns on mental health. Finally, a more systematic 
analysis that goes beyond the sample size of the current study as well as those previously published and psychiatric ED admissions during various phases of the pandemic is warranted.

\section{Conclusions}

The observations described in this study have important pragmatic implications concerning the organization of psychiatric ED personnel to best accommodate these clinical and epidemiological trends. Our findings also provide a foundation for further research to elucidate the long-term consequences of lockdown on mental health. The right to benefit from mental health services [46], even during a lockdown, seems to emerge as a pivotal factor for avoiding the "rebound" effect during the post-lockdown period. We believe that future challenges and perspectives should include research on both, general and clinical population, with a larger number of patients and a longer observation period.

\section{Abbreviations}

Cl: confidence interval; COVID-19: Coronavirus disease 19; ED: Emergency department; EST: Echelle Suisse de Tri; HUG: University Hospital of Geneva; OR: Odds ratio; SB: Suicidal behavior; SD: Standard deviation; SPSS: Statistical Package of Social Sciences; WHO: World Health Organization

\section{Acknowledgements}

Not applicable.

\section{Authors' contributions}

Conceptualization: JA, AC; methodology: AAm, AAg; software: AAg; formal analysis: AAg; investigation: JA; data curation: JA, AF, LM; writing—origina draft preparation: JA, AC, AAm, AAg; writing-review and editing: SK, GB, PP, AW, GS; supervision: GB, SK, GS and FS. All authors have read and agreed to the published version of the manuscript. The author(s) read and approved the final manuscript.

\section{Funding}

This research received no specific grant from any funding agency in the public, commercial, or not-for profit sectors.

\section{Availability of data and materials}

The datasets used and/or analyzed during the current study are publicly not available due to limitations of ethical approval involving the patient data and anonymity but are available from the corresponding author on reasonable request.

\section{Declarations}

\section{Ethics approval and consent to participate}

The study was conducted according to the guidelines of the Declaration of Helsinki and approved by the Research Ethics Committee of Geneva (Commission cantonale d'éthique de la recherche Genève, registration number 2020-01510, approval date: 29 June 2020). Due to the study design, informed consent was not required, which was approved by the ethics committee.

\section{Consent for publication}

Not applicable.

\section{Competing interests}

None of the authors have any financial disclosure or conflict of interest.

\section{Author details}

${ }^{1}$ Department of Psychiatry and Department of Emergency, Emergency Psychiatric Unit (UAUP), Geneva University Hospitals (HUG), 1211 Geneva, Switzerland. ${ }^{2}$ Adult Psychiatry Division, Department of Psychiatry, University Hospital of Geneva (HUG), Geneva, Switzerland. ${ }^{3}$ Department of Neuroscience, Rehabilitation, Ophthalmology, Genetics, Maternal and Child Health (DINOGMI), Section of Psychiatry, University of Genoa, 16132 Genoa, Italy. ${ }^{4}$ RCCS Ospedale Policlinico San Martino, 16132 Genoa, Italy. ${ }^{5}$ Faculty of Medicine, University of Geneva (UNIGE), 1206 Geneva, Switzerland. ${ }^{6}$ Department of Psychiatry, Service of Liaison Psychiatry and Crisis Intervention (SPLIC), Geneva University Hospitals (HUG), 1211 Geneva, Switzerland. 'Department of Emergency, Emergency Medicine Unit, Geneva University Hospitals (HUG), 1211 Geneva, Switzerland.

Received: 11 June 2021 Accepted: 7 September 2021

Published online: 24 September 2021

\section{References}

1. World Health Organization (WHO). https://www.who.int/fr/emergencies/ diseases/novel-coronavirus-2019. Accessed April 9, 2021.

2. Inglesby TV. Public health measures and the reproduction number of SARSCoV-2. JAMA. 2020;323(21):2186-7. https://doi.org/10.1001/jama.2020.7878.

3. Pfefferbaum B, North CS. Mental health and the Covid-19 pandemic. N Engl J Med. 2020:383(6):510-2. https://doi.org/10.1056/NEJMp2008017.

4. Moreno C, Wykes T, Galderisi S, Nordentoft M, Crossley N, Jones N, et al. How mental health care should change as a consequence of the COVID-19 pandemic. Lancet Psychiatry. 2020;7(9):813-24. https://doi.org/10.1016/S221 5-0366(20)30307-2.

5. Torales J, O'Higgins M, Castaldelli-Maia JM, Ventriglio A. The outbreak of COVID-19 coronavirus and its impact on global mental health. Int J Soc Psychiatry. 2020;66(4):317-20. https://doi.org/10.1177/0020764020915212.

6. Kawohl W, Nordt C. COVID-19, unemployment, and suicide. Lancet Psychiatry. 2020;7(5):389-90. https://doi.org/10.1016/S2215-0366(20)30141-3.

7. Kang L, Ma S, Chen M, Yang J, Wang Y, Li R, et al. Impact on mental health and perceptions of psychological care among medical and nursing staff in Wuhan during the 2019 novel coronavirus disease outbreak: a crosssectional study. Brain Behav Immun. 2020;87:11-7. https://doi.org/10.1016/j. bbi.2020.03.028.

8. Amerio A, Bianchi D, Santi F, Costantini L, Odone A, Signorelli C, et al. COVID-19 pandemic impact on mental health: a web based cross-sectional survey on a sample of Italian general practitioners. Acta Biomed. 2020;91(2): 83-8. https://doi.org/10.23750/abm.v91i2.9619.

9. Pappa S, Ntella V, Giannakas T, Giannakoulis VG, Papoutsi E, Katsaounou P. Prevalence of depression, anxiety, and insomnia among healthcare workers during the COVID-19 pandemic: a systematic review and meta-analysis. Brain Behav Immun. 2020;88:901-7. https://doi.org/10.1016/j.bbi.2020.05.026.

10. Shi L, Lu ZA, Que JY, Huang XL, Liu L, Ran MS, et al. Prevalence of and risk factors associated with mental health symptoms among the general population in China during the coronavirus disease 2019 pandemic. JAMA Netw Open. 2020;3(7):e2014053. https://doi.org/10.1001/jamanetworkopen.2 020.14053 .

11. Fiorillo A, Sampogna G, Giallonardo V, Del Vecchio V, Luciano M, Albert U, et al. Effects of the lockdown on the mental health of the general population during the COVID-19 pandemic in Italy: results from the COMET collaborative network. Eur Psychiatry. 2020;63(1):e87. https://doi.org/10.1192/ j.eurpsy.2020.89.

12. Amerio A, Aguglia A, Odone A, Gianfredi V, Serafini G, Signorelli C, et al. COVID-19 pandemic impact on mental health of vulnerable populations. Acta Biomed. 2020b;91(9-S):95-6. https://doi.org/10.23750/abm.v91i9-S.1 0112.

13. Elmer T, Mepham K, Stadtfeld C. Students under lockdown: comparisons of students' social networks and mental health before and during the COVID19 crisis in Switzerland. PLoS One. 2020;15(7):e0236337. https://doi.org/10.13 71/journal.pone.0236337.

14. Webb LJ. COVID-19 lockdown: a perfect storm for older people's mental health. Psychiatr Ment Health Nurs. 2021;28(2):300. https://doi.org/10.1111/ jpm.12644.

15. Yao H, Chen JH, Xu YF. Patients with mental health disorders in the COVID19 epidemic. Lancet Psychiatry. 2020;7(4):e21. https://doi.org/10.1016/S22150366(20)30090-0. 
16. Holmes EA, O'Connor RC, Perry VH, Tracey I, Wessely S, Arseneault L, et al. Multidisciplinary research priorities for the COVID-19 pandemic: a call for action for mental health science. Lancet Psychiatry. 2020;7(6):547-60. https://doi.org/10.1016/S2215-0366(20)30168-1.

17. Xiang YT, Yang Y, Li W, Zhang L, Zhang Q, Cheung T, et al. Timely mental health care for the 2019 novel coronavirus outbreak is urgently needed. Lancet Psychiatry. 2020;7(3):228-9. https://doi.org/10.1016/S2215-0366(20)3 0046-8.

18. Siam MHB, Nishat NH, Ahmed A., Hossain, M.S. Stopping the COVID-19 pandemic: a review on the advances of diagnosis, treatment, and control measures. J Pathog 2020; 9121429, 1, 12, DOl: https://doi.org/10.1155/2020/ 9121429.

19. Federal Office of Public Health, FOPH [Office Fédéral de la Santé Publique, OFSP]. https://www.bag.admin.ch/bag/en/home/das-bag/aktuell/ medienmitteilungen.msg-id-78233.html. Accessed April 9, 2021.

20. Giachino M, Valera CBG, Rodriguez Velásquez S, Dohrendorf-Wyss MA, Rozanova L, Flauhault A. Understanding the dynamics of the COVID-19 pandemic: a real-time analysis of Switzerland's first wave. Int J Environ Res Public Health. 2020;17(23):8825. https://doi.org/10.3390/ijerph17238825.

21. Sager F, Mavrot C. Switzerland's COVID-19 policy response: Consociational crisis management and neo-corporatist reopening. European Policy Analysis. 2020;6(2):293-304. https://doi.org/10.1002/epa2.1094.

22. Gloster AT, Lamnisos D, Lubenko J, Presti G, Squatrito V, Constantinou M, et al. Impact of COVID-19 pandemic on mental health: An international study. PLoS One. 2020;15(12):e0244809. https://doi.org/10.1371/journal.pone. 0244809.

23. Richter D, Riedel-Heller S, Zürcher SJ. Mental health problems in the general population during and after the first lockdown phase due to the SARS-Cov2 pandemic: rapid review of multi-wave studies. Epidemiol Psychiatr Sci. 2021;30:e27. https://doi.org/10.1017/S2045796021000160.

24. Larkin GL, Beautrais AL. Emergency departments are underutilized sites for suicide prevention. Crisis. 2010;31(1):1-6. https://doi.org/10.1027/0227-591 0/a000001.

25. Ostertag L, Golay P, Dorogi Y, Brovelli S, Bertran M, Cromec I, et al. The implementation and first insights of the French-speaking Swiss programme for monitoring self-harm. Swiss Med Wkly. 2019;149:w20016. https://doi. org/10.4414/smw.2019.20016.

26. Costanza A, Mazzola V, Radomska M, Amerio A, Aguglia A, Prada P, et al. Who consults an adult psychiatric emergency department? Pertinence of admissions and opportunities for Telepsychiatry. Medicina (Kaunas). 2020; 56(6):295. https://doi.org/10.3390/medicina56060295.

27. Ambrosetti J, Macheret L, Folliet A, Wullschleger A, Amerio A, Aguglia A, et al. Impact of the COVID-19 pandemic on psychiatric admissions to a large Swiss emergency department: an observational study. Int J Environ Res Public Health. 2021;18(3):1174. https://doi.org/10.3390/ijerph18031174.

28. Killgore WDS, Cloonan SA, Taylor EC, Albright MC, Dailey NS. Trends in suicidal ideation over the first three months of COVID-19 lockdowns. Psychiatry Res. 2020;293:113390. https://doi.org/10.1016/j.psychres.202 0.113390 .

29. Budimir S, Pieh C, Dale R, Probst T. Severe mental health symptoms during COVID-19: a comparison of the United Kingdom and Austria. Healthcare (Basel). 2021;9(2):191. https://doi.org/10.3390/healthcare9020191.

30. McIntyre A, Tong K, McMahon E, Doherty AM. COVID-19 and its effect on emergency presentations to a tertiary hospital with self-harm in Ireland. Ir J Psychol Med. 2020;38(2):1-7. https://doi.org/10.1017/ipm.2020.116.

31. Ahrens KF, Neumann RJ, Kollmann B, Plichta MM, Lieb K, Tüscher O, et al. Differential impact of COVID-related lockdown on mental health in Germany. World Psychiatry. 2021;20(1):140-1. https://doi.org/10.1002/ wps.20830.

32. Niederkrotenthaler T, Gunnell D, Arensman E, Pirkis J, Appleby L, Hawton K, et al. International COVID-19 suicide prevention research collaboration. International COVID-19 suicide prevention research collaboration. Crisis. 2020;41(5):321-30. https://doi.org/10.1027/0227-5910/a000731.

33. Gunnell D, Appleby L, Arensman E, Pirkis J, Appleby L, Hawton K, et al COVID-19 suicide prevention research collaboration. Suicide risk and prevention during the COVID-19 pandemic. Lancet Psychiatry. 2020;7(6): 468-71. https://doi.org/10.1016/S2215-0366(20)30171-1.

34. Costanza A, Di Marco S, Burroni M, Corasaniti F, Santinon P, Prelati M, et al. Meaning in life and demoralization: a mental-health reading perspective of suicidality in the time of COVID-19. Acta Biomed. 2020;91:e2020163.
35. Banerjee D, Kosagisharaf JR, Sathyanarayana Rao TS. 'The dual pandemic' of suicide and COVID-19: a biopsychosocial narrative of risks and prevention. Psychiatry Res. 2021;295:113577. https://doi.org/10.1016/ j.psychres.2020.113577.

36. John A, Pirkis J, Gunnell D, Appleby L, Morrissey J. Trends in suicide during the covid-19 pandemic. BMJ. 2020;371:m4352. https://doi.org/10.1136/bmj. m4352.

37. Pirkis J, John A, Shin S, Shin S, DelPozo-Banos M, Arya V, et al. Suicide trends in the early months of the COVID-19 pandemic: Interrupted time series analysis of preliminary data from 21 countries. Lancet Psychiatry 2021 (Epub ahead of print, 13 April. 2021).

38. Gijzen M, Shields-Zeeman L, Kleinjan M, Kroon H, van der Roest H, Bolier L, et al. The bittersweet effects of COVID-19 on mental health: results of an online survey among a sample of the Dutch population five weeks after relaxation of lockdown restrictions. Int J Environ Res Public Health. 2020; 17(23):9073. https://doi.org/10.3390/ijerph17239073.

39. O'Connor RC, Wetherall K, Cleare S, McClelland H, Melason AJ, Niedzwiedz $\mathrm{CL}$, et al. Mental health and well-being during the COVID-19 pandemic: longitudinal analyses of adults in the UK COVID-19 Mental Health \& Wellbeing study. Br J Psychiatry. 2020:1-8.

40. Attal JH, Lurie I, Neumark Y. A rapid assessment of migrant careworkers' psychosocial status during Israel's COVID-19 lockdown. Isr J Health Policy Res. 2020;9(1):61. https://doi.org/10.1186/s13584-020-00422-0.

41. Aragona M, Tumiati MC, Ferrari F, Viale S, Nicolella G, Barbato A et al. Psychopathological effects of the Coronavirus (Sars-CoV-2) imposed lockdown on vulnerable patients in treatment in a mental health outpatient department for migrants and individuals in poor socioeconomic conditions. Int J Soc Psychiatry (Epub ahead of print, Jan 13, 2021).

42. Shore $J H$, Hilty DM, Yellowlees P. Emergency management guidelines for telepsychiatry. Gen Hosp Psychiatry. 2007;29(3):199-206. https://doi.org/10.1 016/j.genhosppsych.2007.01.013.

43. Joiner TE. Why people die by suicide? Harvard University press 2005.

44. Baertschi M, Costanza A, Richard-Lepouriel H, Pompili M, Sarasin F, Weber K, et al. The application of the interpersonal-psychological theory of suicide to a sample of Swiss patients attending a psychiatric emergency department for a non-lethal suicidal event. J Affect Disord. 2017;210:323-31. https://doi. org/10.1016/j.jad.2016.12.049.

45. Costanza A, Ambrosetti J, Wyss K, Bondolfi G, Sarasin F, Khan R. Prévenir le suicide aux urgences: de la "Théorie Interpersonnelle du suicide » à la connectedness [prevention of suicide at emergency room: from the interpersonal theory of suicide to the connectedness]. Rev Med Suisse. 2018;14(593):335-8.

46. Forman L. Decoding the right to health: what could it offer to global health? Bioethica Forum. 2015:8:91-7.

\section{Publisher's Note}

Springer Nature remains neutral with regard to jurisdictional claims in published maps and institutional affiliations.
Ready to submit your research? Choose BMC and benefit from:

- fast, convenient online submission

- thorough peer review by experienced researchers in your field

- rapid publication on acceptance

- support for research data, including large and complex data types

- gold Open Access which fosters wider collaboration and increased citations

- maximum visibility for your research: over $100 \mathrm{M}$ website views per year

At $\mathrm{BMC}$, research is always in progress.

Learn more biomedcentral.com/submissions 